\title{
Clinico-Pathological Correlation of Hysterectomy Specimens for Abnormal Uterine Bleeding in Peri Menopausal Women
}

\author{
Author \\ Dr Sujeet Kumar Mandal, MD Pathology
}

Assistant Professor, Dept. of Pathology, Jawaharlal Nehru Medical College, Bhagalpur, Bihar

\begin{abstract}
Background: Abnormal Uterine Bleeding (AUB) - a term used to describe any type of bleeding that does not fall within the normal ranges for amount, frequency, duration, or cyclicity. The most common presentations are menorrhagia, polymenorrhoea, metrorrhagia, and intermenstrual bleeding. AUB during premenopausal period poses a diagnostic challenge to clinician and pathologist, as early diagnosis and treatment depends on that.

Aims and Objectives: To Correlate clinical and histopathological pattern in women with peri menopausal bleeding by studying hysterectomy specimens.

Material and Methods: After obtaining institutional Ethical Committee approval and written informed consent, hysterectomy specimens of 200 patients with abnormal uterine bleeding were studied for histopathological examination during the period of December 2014to December 2016.

Results: Mean age of cases was $41.2 \pm 6.8$ years. Majority of the cases of peri menopausal uterine bleeding was in age group of 45 - 55 years $(61 \%)$. Disuterine bleeding, Fibroid, DUB with PID was commonest indications for which hysterectomy was indicated. Non Descent Vaginal Hysterectomy was commonest hysterectomy procedure performed (64\%). The most common histopathological finding was leimyoma found in $36.5 \%$ of cases, followed by adenomyosis which was found in $13.5 \%$ cases.

Conclusion: Leiomyoma are the most common benign conditions found in hysterectomy specimens with peak incidence at 45-55 years. Histopathology is mandatory for confirming diagnosis and ensuring optimal management.
\end{abstract}

\section{INTRODUCTION}

Perimenopause is the period preceding menopause by 3-4years and followed by 1year of amenorrhoea from the final menstrual period. It is characterized by menstrual irregularities and increasing months of amenorrhoea (1) .In the recent past, perimenopause has been recognized and addressed as a biologic process distinct from menopause. However, a better practical definition is the phase preceding the onset of menopause, generally occurring around 40-50 years of age (beginning at age 47.5, lasting for 4 years) during which the regular cycle of a woman transitions to a pattern of irregular cycles Perimenopause may serve as an ideal time for improvement of health screening, recognition of otherwise silent diseases and motivation for a healthier life style for the rest of the patient's life ${ }^{(2)}$. Menopause occurs at an average age of 51.4 yrs with a range from 40$58 \mathrm{yrs}$. Age of onset of perimenopause in more than $95 \%$ women is $39-51$ years and the duration is $2-8 y$ rs in more than $95 \%$ women. Therefore, we focus on the age group $39-59$ yrs. 
Abnormal Uterine Bleeding (AUB)-a term used to describe any type of bleeding that does not fall within the normal ranges for amount, frequency, duration, or cyclicity. The most common presentations are menorrhagia, polymenorrhoea, metrorrhagia, and intermenstrual bleeding. Abnormal uterine bleeding occurs in 9 to 14 percent of women between menarche and menopause, significantly impacting quality of life and imposing financial burden ${ }^{(3)}$.

The two most important underlying pathology of AUB are leiomyoma and adenomyosis. Adenomyosis, which is a benign uterine disease defined as the downward growth of endometrial basal layer into the myometrium. Although various methods such as ultrasound scan and magnetic resonance imaging have shown high levels of accuracy for the noninvasive diagnosis of adenomyosis. Hysterectomy and microscopic evaluation of the samples are still the only ways of definite diagnosis of adenomyosis ${ }^{(4,5)}$.

Patients with a history of anovulation, obesity, hypertension, diabetes, and exogenous estrogen use are at an increased risk for hyperplasia and adenocarcinoma. Early evaluation in the perimenopausal and postmenopausal women is essential to confirm the exact nature of the lesion and to rule out malignancy ${ }^{(6,7)}$.

\section{AIMS AND OBJECTIVES}

To Correlate clinical and histopathological pattern in women with peri menopausal bleeding by studying hysterectomy specimens.

\section{MATERIAL AND METHODS}

After obtaining institutional Ethical Committee approval and written informed consent, hysterectomy specimens of 200 patients with abnormal uterine bleeding were studied for histopathological examination during the period of December 2014 to December 2016.

\section{Method of collection of data}

The data for prospective study will be obtained from requisition with tissue specimens received with $10 \%$ formalin. After adequate fixation the specimens will be subjected for gross examination. After tissue processing, 3-5 micron thick sections will be taken and stained with haematoxylin and eosin and special stains whenever necessary.

\section{Study Period:}

Two year prospective study from December 2014 to December 2016.

\section{Inclusion Criteria}

1. All hysterectomy specimens from perimenipausal women with abnormal bleeding

2. Age group within 35 to 56 years

\section{Exclusion Criteria}

1. Hysterectomy specimens from women with systemic causes of bleeding

2. Pregnancy related causes

3. Abnormal cervical cytology

4. Trauma, foreign body etc.

\section{Sample Size}

Based on previous studies and statistical formula , a sample size of 200 was determined with an alpha error of 0.05 and power of 0.95 .

\section{Statistical Methods}

In the statistical analysis of our study, Continuous variables were presented as mean for parametric data and median if the data is non parametric or skewed. Student $t$ test was applied for calculation of statistical significance whenever the data followed normative distribution. Mann whitney test was applied whenever data followed non normative distribution. Categorical variables was expressed as frequencies and percentages. Nominal categorical data between the groups was compared using Chi-square test or Fisher's exact test as appropriate. $\mathrm{P}<0.05$ was taken to indicate a statistically significant difference. Minitab version 17 was used for computation of statistics.

\section{RESULTS}

Table.1. Age profile of the study group

\begin{tabular}{|l|c|c|}
\hline AGE & NO. OF CASES & PERCENTAGE \\
\hline $35-45$ & 69 & $34.50 \%$ \\
\hline $45-55$ & 122 & $61.00 \%$ \\
\hline $55-65$ & 8 & $4.00 \%$ \\
\hline Above 65 & 01 & $0.50 \%$ \\
\hline
\end{tabular}


Diagram . 1. Age profile of the study group

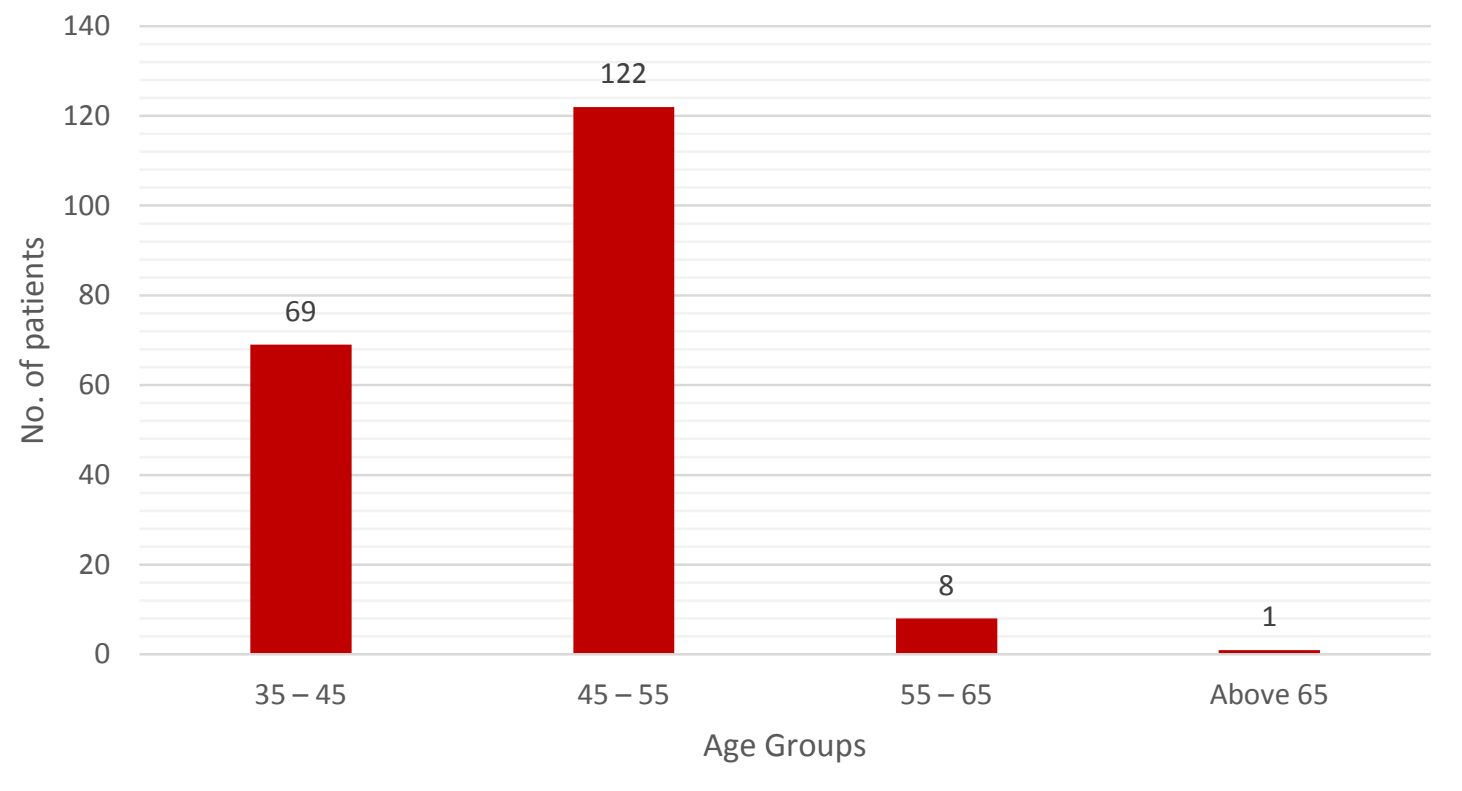

Table.2. Indications for Hysterectomy

\begin{tabular}{|l|c|c|}
\hline INDICATION & NUMBER & PERCENTAGE \\
\hline DUB & 86 & $43.00 \%$ \\
\hline FIBROID & 54 & $27.00 \%$ \\
\hline ADENOMYOSIS & 21 & $10.50 \%$ \\
\hline DUB with PID & 23 & $11.50 \%$ \\
\hline ENDOMETRIAL POLYP & 6 & $3.00 \%$ \\
\hline ENDOMETRIOSIS & 4 & $2.00 \%$ \\
\hline CIN & 4 & $2.00 \%$ \\
\hline OTHERS & 2 & $1.00 \%$ \\
\hline
\end{tabular}

Diagram.2. Indications for Hysterectomy

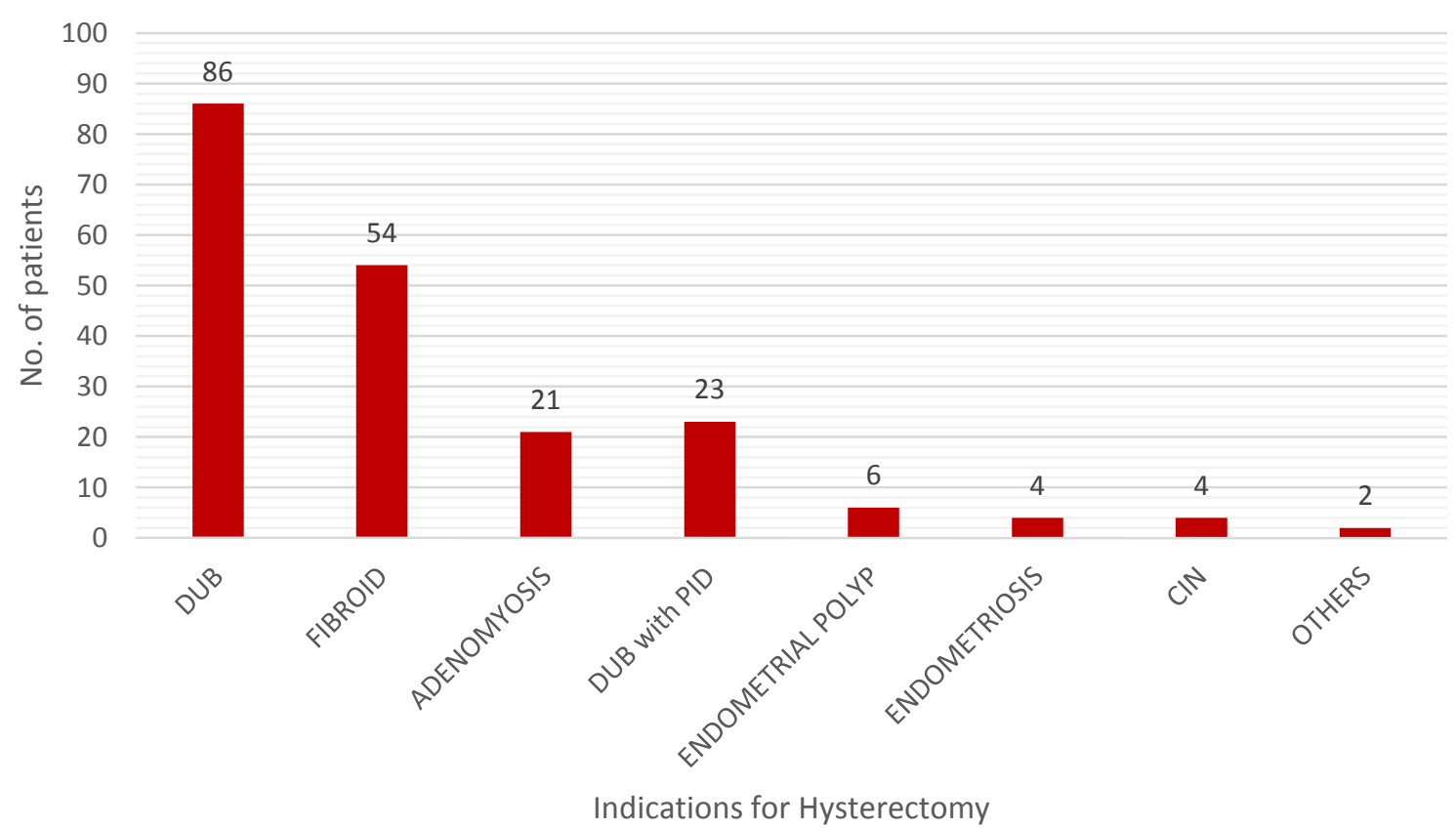


Table.3. Types of Hysterectomy

\begin{tabular}{|l|c|c|}
\hline TYPES OF HYSTERECTOMY & NUMBER & PERCENTAGE \\
\hline NDVH & 128 & $64.00 \%$ \\
\hline NDVH WITH BSO & 6 & $3.00 \%$ \\
\hline NDVH WITH RIGHT SO & 8 & $4.00 \%$ \\
\hline NDVH WITH LEFT SO & 11 & $5.50 \%$ \\
\hline TAH & 21 & $10.50 \%$ \\
\hline TAH WITH BSO & 11 & $5.50 \%$ \\
\hline TAH WITH RIGHT SO & 8 & $4.00 \%$ \\
\hline TAH WITH LEFT SO & 6 & $3.00 \%$ \\
\hline RADICAL HYSTERECTOMY & 1 & $2.00 \%$ \\
\hline
\end{tabular}

Diagram.3. Types of Hysterectomy

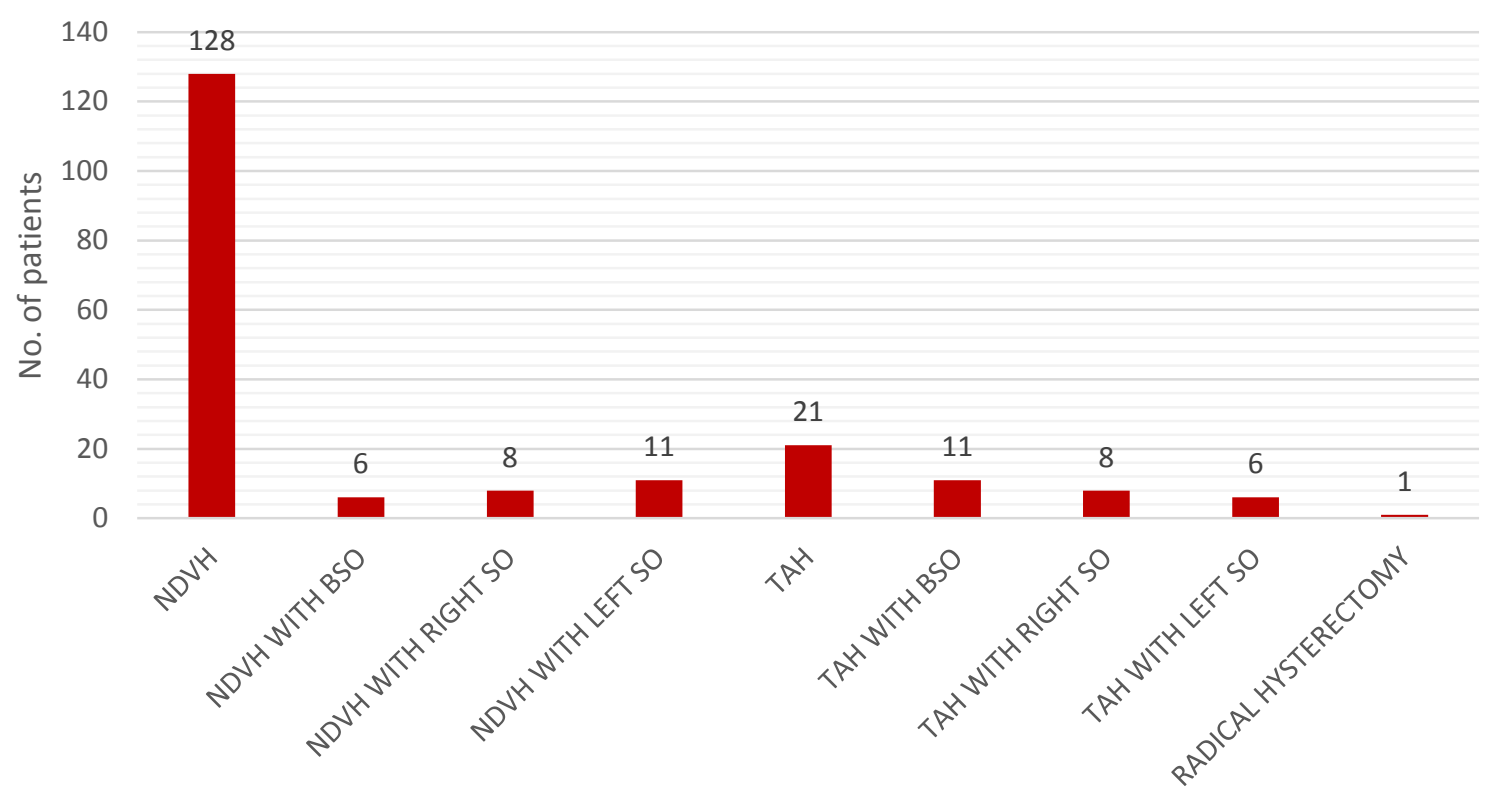

Indications for Hysterectomy

Table.4. Histopathological Diagnosis

\begin{tabular}{|l|c|c|}
\hline HISTOPATHOLOGICAL DIAGNOSIS & NUMBER & PERCENTAGE \\
\hline Fibroid & 73 & $36.50 \%$ \\
\hline Adenomyosis & 27 & $13.50 \%$ \\
\hline Combined leiomyoma \&adenomyosis & 8 & $4.00 \%$ \\
\hline Endometrial hyperplasia & 18 & $9.00 \%$ \\
\hline Endometrial polyp & 6 & $3.00 \%$ \\
\hline Atrophic endometrium & 6 & $3.00 \%$ \\
\hline Ovarian cyst / tumour & 3 & $1.50 \%$ \\
\hline CIN & 4 & $2.00 \%$ \\
\hline Endometrial Carcinoma & 1 & $0.50 \%$ \\
\hline No significant pathology & 54 & $27.00 \%$ \\
\hline
\end{tabular}


Diagram.4. Histopathological Diagnosis

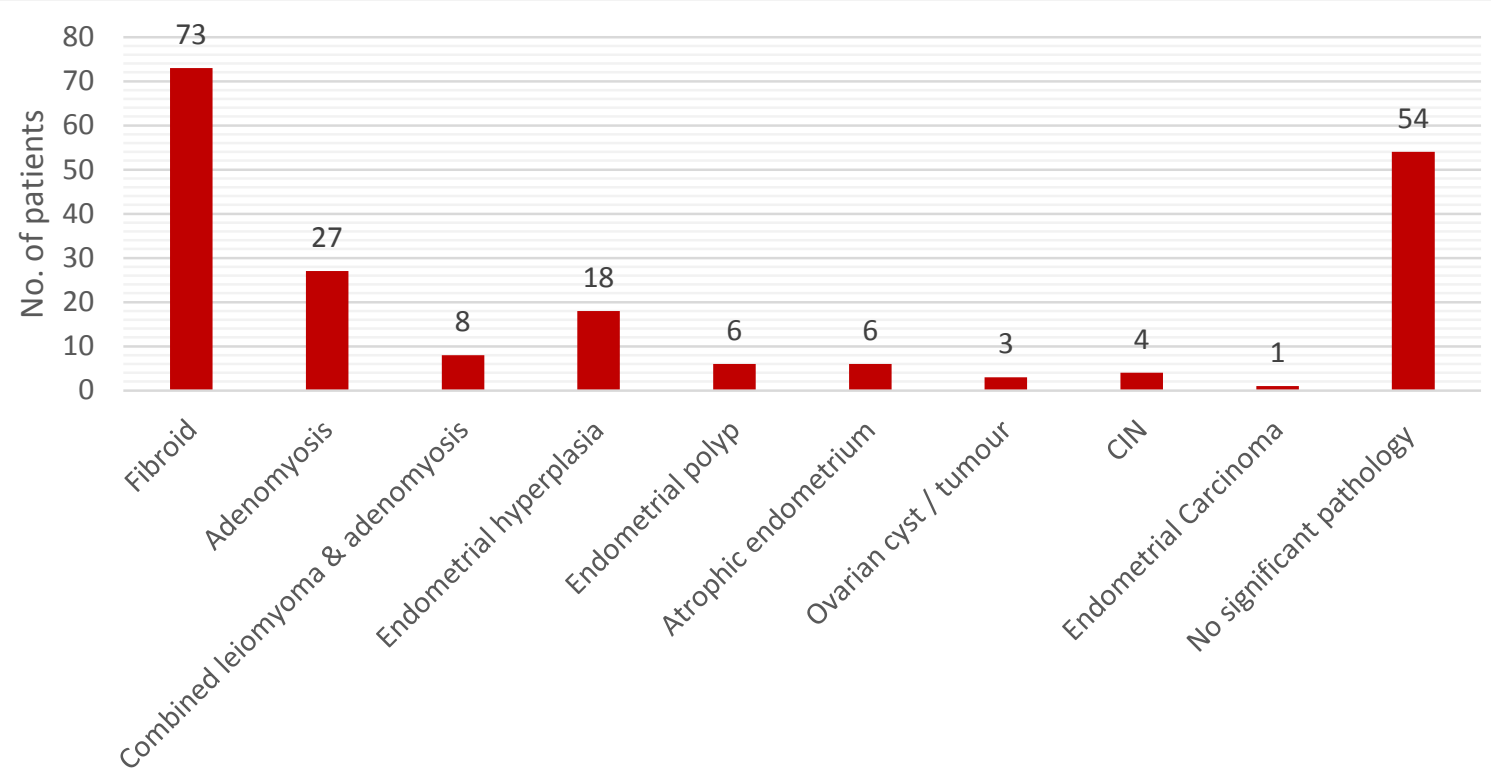

Histopathological diagnosis

\section{DISCUSSION}

In our study, mean age of cases was $41.2 \pm 6.8$ years. Majority of the cases of peri menopausal uterine bleeding was in age group of $45-55$ years (61\% ).In a similar study by Yogesh Neena et al , maximum cases $(54.16 \%)$ were in $45-55$ years $^{(8)}$. In study by Talukdar B et al, $67.97 \%$ of patients were in in age group of $45-55$ years ${ }^{(9)}$. Thus age group of 45 - 55 seems to be most vulnerable age group for uterine bleeding in peri menopausal women.

In our study, Disuterine bleeding, Fibroid, DUB with PID was commonest indications for which hysterectomy was indicated. In a study by Yogesh Neena et al, Disuterine bleeding, Fibroid and Adenomyosis constituted commonest indication for hysterectomy.

In our study, Non Descent Vaginal Hysterectomy was commonest hysterectomy procedure performed $(64 \%)$. In a study by Yogesh Neena et al, NDVH constituted $65.97 \%$ cases. The most common histopathological finding was leimyomafound in $36.5 \%$ of cases, followed by adenomyosis which was found in $13.5 \%$ cases. In our study, The leiomyoma ranged in number from one to seven. A single leiomyoma was seen in 62 $\%$ cases and Multiple leiomyomas were seen in 38 $\%$ cases. In a study by Yogesh Neena et al, the most common histopathological finding was leiomyoma found in 71 cases, followed by adenomyosis which was found in 35 cases. The leiomyoma ranged in number from one to six. A single leiomyoma was seen in 35 cases. Multiple leiomyomas were seen in 36 cases.

In a study by Ravindra et al in 120 perimenopausal women with abnormal uterine bleeding, Fibroid uterus, DUB, and adenomyosis and were the common causes of abnormal uterine bleeding ${ }^{(10)}$.

In a similar study, Khreisat et al. reported that adenomyosis is a common finding in hysterectomy specimen. They found nearly $37 \%$ of all the specimens proved to be adenomyosis whereas the second most common finding was fibroid uterus.

In their study, Sajjad et al. observed 39\% cases of leiomyomas, followed by adenomyosis in $19 \%$ cases. 5\% cases showed dual pathology consisting of both leiomyomas and adenomyosis. ${ }^{(12)}$.

Gupta et al. in their study observed that menorrhagia was the most common complaint and fibroid uterus was responsible for AUB in 53\% of women ${ }^{(13)}$.

Perveen and Tayyab reviewed 54 elective abdominal hysterectomies and revealed that menstrual disturbance/ DUB is a leading 
indication $(27.7 \%)$ of hysterectomy and leiomyoma is the commonest (59. 2\%) pathological lesion ${ }^{(14)}$.

Most cross national studies also showed leiomyomas as the most common pathological lesion with a variable frequency. Its incidence is $25.8 \%$ in Abbah City of Saudi Arabia, $78 \%$ in the USA, $48 \%$ in Nigeria, and $8 \%$ in Sweden. Genetical and racial influences are thus apparent on the prevalence of uterine leiomyoma ${ }^{(15,16)}$.

\section{CONCLUSION}

Leiomyoma are the most common benign conditions found in hysterectomy specimens with peak incidence at 45-55 years. Histopathology is mandatory for confirming diagnosis and ensuring optimal management.

\section{Limitation of The Study}

Duration of surgery and blood loss were not considered in our study.

\section{Ethical committee approval}

Taken

\section{Financial support and sponsorship}

Nil

\section{Conflicts of interest}

There are no conflicts of interest

\section{BIBILOGRAPHY}

1. Aravindpallipady, Sandyaillanthody et al. A clinic-morphological spectrum of the non-neoplastic lesions of the Uterine cervix at AJ Hospital,Mangolore;Journal of clinical and diagnostic research. 2011June,vol-5(3):546-550.

2. Aytekin Tokmak,Ali Irfan Guzel et al.Clinical significance of Atypical squamous cells of undetermined significance in detecting Preinvsive cervical lesions in post-menopausal Turkish women, Asian pacific Journal of cancer prevention, vol 15,2014,6639-6641.

3. Veena S Naik,Jyoti D Rege et al;Pathology of genital tract in post-menopausal bleeding,dept of pathology. T.N.Medical college and BYL nairch. hospital, Mumbai, Bombay hospital Journal,1996.

4. Côté I, Jacobs P, Cumming DC. Use of health services associated with increased menstrual loss in the United States. Am J Obstet Gynecol. 2003;188:343-8.

5. Dr.BangalVB,Patil NA et al,Colposcopy guided management of cervical erosions in Rural population,Scholars journal of Applied medical sciences.,2014;IC:261265.

6. Ali Hassan Al-Timim,NadiaMudher AlHilli et al,Post-menopausal bleeding: Clinicopathological study in Babel province between the years 2000-2009

7. Rimsza ME. Dysfunctional uterine bleeding. Pediatr Rev. 2002;23:227-33.

8. Yogesh Neena, Bhaskar Honey, "Clinicopathological correlation of hysterectomy specimens for abnormal uterine bleeding in rural area". Journal of Evolution of Medical and Dental Sciences 2013; Vol2, Issue 39, September 30; Page: 7506-7512.

9. Talukdar B, Mahela S. Abnormal uterine bleeding in perimenopausal women: Correlation with sonographic findings and histopathological examination of hysterectomy specimens. Journal of MidLife Health. 2016;7(2):73-77

10. Sarfraz TS, Tariq H. Histopathologic findings in menorrhagia a study of 100 hysterectomy specimens. Pak J Pathol. 2005;16:83-5

11. Khreisat B, Al-Rawabdeh S, Duqoum W, Al Qudah M. Adenomyosis: Frequency of hysterectomy in histopathological specimens at two Jordanian military hospitals. JRMS. 2011;18:76-9.)

12. Sajjad M, Iltaf S, Qayyum S. Pathological findings in hysterectomy specimens of patients presenting with menorrhagia in different age groups. Ann Pak Inst Med Sci. 2011;7:160-2.

13. Gupta A, Rathore AM, Manaktala U, Rudingwa P. Evaluation and histopathological correlation of abnormal 
uterine bleeding in perimenopausal women. IJBAR. 2013;04:509-13.)

14. Shergill SK, Shergill HK, Gupta M, Kaur

S. Clinicopathological study of hysterectomies. J Indian Med Assoc. 2002; 100:238-9, 246.

15. Baird DD, Dunson DB, Hill MC, Cousins D, Schectman JM. High cumulative incidence of uterine leiomyoma in black and white women: Ultrasound evidence. Am J Obstet Gynecol. 2003;188:100-7

16. Adelusola KA, Ogunniyi SO. Hysterectomies in Nigerians: Histopathological analysis of cases seen in Ile-Ife. Niger Postgrad Med J. 2001;8:37-40. 